\title{
Exploration on the Construction Path of "Double- Position" Teaching Staff for Applied Undergraduate
}

\author{
Lingyan Meng \\ Department of Economics and Management \\ Jining University \\ Qufu, Shandong, 273115, China \\ mly7312@163.com
}

\begin{abstract}
The construction of "double-position" teaching staff is an important support for personnel training in applied colleges and universities. Following literature review, field investigation, expert interview and other research methods, this work screened the restrictive factors of "double-position" teaching staff construction in applied colleges and universities, and revealed the problems such as vague identification standard, single channel of teacher introduction, lack of evaluation and incentive mechanism and lack of teacher training. Based on the four dimensions of perfecting qualification certification, perfecting incentive mechanism, innovating talent introduction mode and building teacher training base, this work explored the construction path of "double-position" teaching staff, and provided theoretical guidance and experience reference for the construction of "double-position" teaching staff in colleges and universities.
\end{abstract}

Keywords-Double-position teaching staff; Incentive mechanism; school-enterprise cooperation; Applied type; Teacher training

\section{INTRODUCTION}

From the perspective of national policy, "double-position" teaching staff has gone through three stages of development: concept introduction, connotation deepening and system construction. In 1990, China Education Newspaper first put forward the concept of "double-position" teachers, which set off a heated discussion on "double-position" teachers. In 1995, in the "Notice of the State Educational Commission on the Construction of Developing Demonstrative Vocational Universities", more than one-third of "double-position" teachers were considered as one of the basic conditions for applying for pilot construction of demonstrative vocational universities, and "double-position" teachers began to be included in the scope of the national policy system. In 1997 "Several Opinions of the State Educational Commission on the Setting of Higher Vocational Schools" and 1998 "Principles and Opinions for Deepening the Reform of Vocational Education Teaching in the 21st Century", the concept of "double-position" teachers is used, which means that teachers in vocational colleges should have dual abilities (i.e., educational and teaching abilities and professional practical abilities). However, these policies have not clearly explained the specific connotation of "double-position" teachers. In 1999, the "Decision of the CPC Central Committee and the State Council on Deepening Education Reform and
Comprehensively Promoting Quality Education" put forward: "Accelerating the construction of a 'double-position' teaching staff with both teacher qualifications and other professional and technical positions". In 2010, the State Council deliberated and adopted the "Outline of the National Medium and Long Term Education Reform and Development Plan (2010-2020)". which clearly put forward the general requirements for strengthening the construction of teachers in vocational colleges and universities and focusing on "double-position" teachers. On the one hand, it points out the connotation of "double-position" teachers (i.e., "holding professional and technical qualification certificates and vocational qualification certificates"). On the other hand, it points out the construction path of "doubleposition" teaching staff (i.e., relying on relevant colleges and universities and large and medium enterprises to build a "double-position" teachers training base, increasing training efforts and enhancing the ability of vocational college teachers to obtain double certificates). In 2017, the "Opinions on Fully Deepening the Reform of Teaching Staff Construction in the New Era" clearly pointed out that the construction of teaching staff should be "classified and implemented". It mainly involves the quality improvement plan of double-position teachers, the joint training of schools and enterprises, part-time teaching, assessment and evaluation, etc. To a certain extent, it eliminates some policy obstacles that restrict the construction of double-position teachers for a long time in practice. The report of the 19th National Congress further proposed "speeding up the construction of first-class universities and disciplines and realizing the connotative development of higher education", and regarded "cultivating high-quality teachers" as an important measure to realize the modernization of education.

Based on the connotation multiplicity, status specificity, requirement complexity and evaluation index diversification of "double-position" teachers, Applied undergraduate colleges and universities should implement the spirit of the 19th National Congress and "Opinions on Fully Deepening the Reform of Teaching Staff Construction in the New Era", and clarify the orientation of running a school. It should strengthen the implementation of the system, adhere to the principle of "classified and implemented", and construct a systematic and institutionalized "double-position" teachers management and training system. This work systematically combed and analyzed the achievements and existing problems in the construction of the "double-position" teaching staff, and put forward some suggestions for improvement from the 
perspective of optimizing the institutional environment and introducing and cultivating innovative talents. It is of great practical significance to enrich the experience of "doubleposition" teaching staff construction and to advance the theoretical research of higher education teachers.

\section{PRoblems Existing IN THE CONSTRUCTION OF DOUBLE- POSITION TEACHING STAFF}

\section{A. "Double-position" teachers identification standard is vague}

The criteria for identifying "double-position" teachers are the logical starting point for the construction of "doubleposition" teachers. At present, there are many forms of expressions such as "double certificate theory" [1], "double title theory" [2], "double identity theory" [3], "double quality theory" [4], etc. Based on the different understanding and grasp of the connotation for "double-position", the provinces, municipalities and colleges have different standards and lack of systematic index system, which brings obstacles and confusion to the construction of "double-position" teachers. Some colleges and universities adopt the "double certificate theory" to identify "double-position" teachers. Although the practicability is strong, the "double certificate" teachers do not have "double quality" and "double ability". The identified "double-position" teachers are not true. At present, In order to meet the ministry of education personnel training level assessment, many applied undergraduate colleges and universities require professional teachers to become "doubleposition" teachers by means of short-term enterprise posttraining and vocational qualification certificates, so as to increase the proportion of "double-position" teachers. This formalistic approach has little effect on improving the skill level of professional teachers. The vagueness and differentiation of the criteria for identifying "double-position" teachers lead to the tendency of differentiation, short-term and formalization in the practice of team building.

\section{B. Single channel for teacher introduction and lack of practical skills}

At present, the majority of teachers in applied undergraduate colleges and universities are from school to school and from classroom to classroom. There is a single channel to introduce young teachers, generally for graduates of master's or doctor's degree in research universities. Despite their high educational background, high theoretical level and strong academic research ability, they are disconnected from theory and practice and lack of post skills. The problem of "opening machines on the blackboard and teaching on the PPT" is more prominent. While undertaking heavy teaching tasks, the old teachers put a great deal of energy on hard indicators such as scientific research papers, topics and works. They have no time to take into account professional skills training, and the school has no certain incentive and restraint mechanism to promote teachers to improve their practical operation skills. Teachers' classroom teaching content originates from books. Scientific research activities pay more attention to pure theoretical research, and they will say and not do it. The problem of teachers' weak practical teaching ability is widespread. The school pays insufficient attention to the cultivation of teachers' practical ability and lacks investment. The requirement for teachers' ability still remains in the traditional school-running orientation and personnel training standards, which can not meet the transformation requirements of applied universities. It overemphasizes the level of theoretical teaching and scientific research, which affects the quality of applied talents training.

\section{Lack of "Double-position" teachers evaluation incentive mechanism}

The teacher management system is an important guarantee for the construction of "double-qualified" teaching staff. At present, the construction of "double-position" teachers management system in applied colleges universities is quite weak, and the supporting system needs to be further improved. First, the assessment and evaluation mechanism is not perfect. In the assessment and evaluation of "double-position" teachers, they attach importance to access, despise exit, value result management and despise process evaluation. Once "doubleposition" teachers are identified, they will not conduct a dynamic assessment any more, and there is no exit mechanism. Second, the incentive and restraint mechanism is not perfect. Many applied undergraduate colleges and universities attach importance to academy and theory, and light technology and application. It does not attach importance to the development of the talent training model to the combination of work with study, the transformation of the curriculum system to pay equal attention to both theory and practice, and the construction of the teaching staff to the direction of "double-position". The existing policies are not strong enough to motivate and restrict teachers to obtain the recognition of "double-position", and "double-position" has not been used as a rigid evaluation index for teachers. Third, in the professional title appraisal and performance appraisal, the traditional evaluation standard is followed, which is deviated from the "double-position and double-ability" teachers training standard in applied colleges and universities. It focuses on theoretical research results, and not focuses on technology application and conversion capability. Teachers' technical certificates, professional qualifications and practice experience are too low in the evaluation indicators. The performance appraisal is inclined to "research-oriented" teachers, and the level of teachers' practical operation is not included in the performance appraisal evaluation system, which cannot motivate teachers to improve their enthusiasm of practical teaching ability from the system. Due to the "insufficient system supply", policies are inefficient or ineffective.

\section{Weak links in teacher training}

For a long time, applied undergraduate colleges and universities have some problems, such as misunderstanding bias and weak awareness of teacher training. The training system of "double-position" teachers is imperfect, inefficient and formalized. It attaches importance to pre-job training, theoretical training and on-campus training, and despises onthe-job training, practical skills training and off-campus training. The problems such as single training channel, imperfect training mechanism, low level of training, weak specialty and inadequate implementation of funds are 
prominent. In view of the fact that teachers have no professional background, the competent training departments in schools are unable to implement sub-professional practical skills training. There is no ability to propose individualized training plans for each teacher, and no corresponding training for part-time teachers outside school, which will affect the integrity of teachers' knowledge structure and the quality of personnel training in teaching practice.

\section{EXPLORATION OF THE CONSTRUCTION PATH OF "DOUBLE- POSITION" TEACHING STAFF}

The construction of "double-position" teaching staff does not require all teachers to be "double-position" teachers, which is neither realistic nor necessary. However, professional core courses and core post ability training tasks must be held by "double-position" teachers, so teachers should be classified and stratified management (i.e., the team is composed of some teachers with high theoretical teaching ability and some teachers with practical experience, so as to achieve the synergy and complementary of team members.)

\section{A. Perfecting the professional certification and supervision and assessment system for "double-position" teachers}

It must further strengthen the top-level design and perfect the "double-position" teachers management system. The establishment of "double-position" teachers professional certification system is an important basis for the construction of "double-position" teachers team system. A qualification certification group composed of educational administrative departments, industries, enterprises and universities shall be established to determine the minimum quality standards for "double-position" teachers through a scientific indicator system. We can comprehensively consider the development stage and professional layout of the university, focus on the regional industrial structure, regional advantages and economic development level, and establish the "double-position" teachers certification standards in line with the long-term development plan of the university.

It is necessary to strengthen supervision and evaluation, and promote the effective implementation of the "double-position" teachers management system. It is also necessary to further improve the education supervision system at all levels, establish accountability mechanisms, implement the responsibility of the "double-position" teachers policy, and strengthen the supervision and evaluation of the "doubleposition" teachers policy. In the process of supervision and evaluation, on the one hand, the implementation process and implementation results of "double-position" teachers management should be evaluated. On the other hand, the implementation benefits, efficiency and value of the system should be judged, and suggestions should be provided for the improvement of the system, so that the "double-position" teachers system can better guide the practice of higher education.

It is necessary to establish a dynamic evaluation system. The evaluation criteria and methods of "double-position" teachers should be formulated, and the enterprise acceptance and students acceptance should be included in the evaluation criteria of "double-qualified" teachers. According to the different stages of "double-position" teachers' professional development, the system of graded assessment and evaluation criteria, annual registration of teacher qualification, merit promotion and dynamic adjustment is formulated. The qualification of "double-position" teachers is certified and audited in a five-year cycle, and the access mechanism and exit mechanism of "double-position" teachers are perfected. Through the goal incentive to promote the professional development of teachers, we strive to create a new concept, high quality, mobile and competitive "double-position" teaching staff.

\section{B. Improving the incentive mechanism for "double-position" teachers}

An effective incentive mechanism is an important guarantee for the construction of "double-position" teachers. While continually improving the training system for "doubleposition" teachers, it is necessary to focus on promoting the construction of teachers incentive mechanism. Supported by a sound personnel system, wage system and social security system, teachers' enthusiasm is stimulated through the allocation measures of performance distribution and job title evaluation, and the guiding and leading role of the system is brought into full play. On the one hand, the salary system reflects the difference between ordinary teachers and "doubleposition" teachers. The reward performance salary of "doubleposition" teachers is obviously higher than that of ordinary teachers, so as to give full play to the incentive role of performance and salary and form benign competition. On the other hand, in the promotion of posts and the evaluation of professional titles, teachers' practical operation ability should be fully considered, so as to arouse their initiative and enthusiasm to develop into "double-position and doubleability" [5], so that "double-position" teachers can see their own bright development prospects. At the same time, it can effectively use negative incentives to sort out the "doubleposition" teachers who have more problems with students or teachers.

\section{Innovating the way of introducing and training talents}

We will broaden the channels for talent introduction, incorporate the "workable craftsman" of the enterprise industry into teaching resources, and unblock the channels of enterprise technology to the concurrently serving as teachers. The introduction methods of receiving, transferring, part-time, flexible employment, etc., will be combined, and the employment mode of fixed preparation and mobile preparation, full-time and part-time employment will be adopted. In accordance with the concept of integration of industry and education, which is "not seeking all, but seeking use, sharing resources, mutually beneficial and win-win", a group technological leaders of enterprises are attracted to applyoriented personnel training posts through flexible ways such as short-term employment, cooperative research, academic consultants and visiting professors. It not only solves the problem (full-time teaching staff) of practical experience and "inbreeding", but also promotes the communication between full-time and part-time teachers, guides the transformation of professional teachers to "double-position", optimizes the 
structure of teachers and catalyzes the construction of "doubleposition" teachers.

Colleges and universities should adhere to the principle of "key training, ensuring quality and applying learning", and strengthen the training of full-time teachers through "multiple channels, multiple levels and all aspects" [6]. Teachers' innovative quality, cross-border cooperative teaching ability, continuous learning ability, psychological quality and service spirit are included in the quality standard of "double-position" teachers. Teachers' actual operation, textbook compilation and practical teaching guidance level are included in the ability standard of "double-position" teachers. Relying on the teacher development center, we should integrate pre-service training with post-service training, implement the "Teacher Professional Quality Training Plan" and "Double-position Teaching Staff Building Plan", guide teachers to form teams, and clarify the rights and obligations of team leaders, teaching backbone and young teachers. Team members will be selected in batches and planned to go to enterprises, research institutions and foreign universities (a line of production, management and service) to receive practical training, so that they can understand the advanced technology, management experience and talent demand of the industry.

\section{Co-construction of teacher training base by school- enterprise}

The key to the construction of "double-position" teaching staff is "school-enterprise co-construction". The deep cooperation between schools and enterprises and the establishment of "teacher training base" is particularly important for the construction of a "double-position" teaching staff with excellent quality, reasonable structure, integration of production and learning, and distinctive characteristics. The base is used as a carrier to promote the integration of production and education. Supported by production and centered on teaching, we should realize the dual identity of school and enterprise personnel, the double backbone of curriculum construction, and promote the two-way circulation of teachers and technicians in enterprises and schools. The university teachers and enterprise backbones will carry out extensive cooperation in the fields of education and teaching, science and technology research and development, and realize the two-way integration of teaching and production practice [7]

\section{E. Innovating the management methods and means of part- time teachers}

We should persist in setting up posts on demand, implement classified employment and management, and select skilled craftsmen to serve as part-time teachers, including four types: management type, backbone type, technician type and training guidance. Personnel department, academic affairs office, school-enterprise cooperation offices and departments shall take part in the appointment, management and service of part-time teachers, and clarify the conditions, procedures, responsibilities and treatment of part-time teachers. Emphasis should be placed on the management of part-time teachers' teaching, scientific research process and achievements. Two methods should be adopted, namely "hiring" and "concurrently". The "hiring" is mainly aimed at the leaders and technical (management) experts of enterprises, and the "appointment, high salary or no salary" method should be adopted to invite them to participate in professional construction. The "concurrently" refers to the employment of enterprise personnel to teach "concurrently" and participate in practical teaching. This has changed the phenomenon that parttime teachers used to attach importance to appointment, entry qualifications and professional titles, and despise management, the performance of practical teaching and scientific research. It solves the key problems in the employment and management of part-time teachers from the system, and provides institutional guarantee for the construction of part-time teachers.

\section{CONCLUSION}

The construction of "double-position" teaching staff is an important support for the transformation of undergraduate universities into applied universities, and also a key link and an important starting point for the reform of higher education. It needs the support of educational resources, policies, systems and other elements inside and outside the university. It is not a quick thing, but a complex and long-term systematic project. In this system engineering, the establishment of a clear "doubleposition" teachers identification standard is the premise. The management of colleges and universities must make clear the orientation of running a school and the goal of personnel training, set up modern educational ideas, and strengthens the understanding of the connotation of "double-position" teachers and the improvement of evaluation criteria. It is the way to build a "double-position and double-ability" teaching staff that combines specialty with the concurrence and reasonable structure. We should strengthen the training of full-time teachers through the combination of inside and outside school, pre-job and post-job, theory and practice. At the same time, we should expand the channels of introducing teachers, integrate the backbone of experts outside school into teaching resources, and realize resource sharing and complementary advantages. The incentive mechanism for sound "double-position" teachers is a guarantee. In order to provide institutional guidance and incentives for the construction of "double-position" teachers, it should build an internal management system suitable for the development of "double-position" teachers, and achieve scientific evaluation and systematic management at the institutional level of title promotion, year-end merit evaluation and performance salary reform. School-enterprise coconstruction of teacher training base is the media and leverage. Taking the training base as the carrier, we should promote the integration of industry and education, and provide opportunities for multi-field and deep cooperation between schools and enterprises. With multiple participation, multiple measures and all elements, the structure of "double-position" teaching staff has been improved and optimized in an all-round way, and the connotative development of applied undergraduate colleges and universities has been promoted.

\section{REFERENCES}

[1] Ministry of Education. Outline of the National Medium and Long Term Education Reform and Development Plan (2010-2020) [Z]. 2010. 
[2] Ministry of Education. Some Opinions on Further Strengthening Vocational Education [Z]. 2004.

[3] State Council. The decision of the CPC Central Committee and the State Council on Deepening Education Reform and Comprehensively Promoting Quality Education [Z]. 1999.

[4] Opinions of the General Office of the Ministry of Education on Strengthening the Construction of Teaching Staff in Higher Vocational (Higher College) Colleges [Z]. 2002.
[5] Ministry of Education, National Development and Reform Commission, Ministry of Finance. Guiding Opinions on Guiding Some Local Universities to Change into Applied Universities [Z]. 2015.

[6] Wang Yiding, Huang Junpeng. Research on Teaching Staff Construction in Applied Universities [J]. Adult Education in China, 2016 (09).

[7] Li Minghui, Zeng Shaowei. Channels, Experience and Enlightenment of the "Double-Position" Teaching Staff in German Vocational Education [J]. Education and Vocational, 2018 (11). 